

\title{
Inhibitory Effect of Polyphenols Extracts from Peanut Shells on the Activity of Pancreatic Lipase in vitro
}

\author{
Yali Yu*, XiaOmeng Sun and Feng Gao
}

Department of Food Science and Engineering, Jilin University, Changchun, P.R. China

*Corresponding author: Fax: +86 431 87835760; Tel: +86 431 87836373; E-mail: yyl_0927@163.com

Received: 21 February 2014;

Accepted: 21 April 2014;

Published online: 25 May 2014;

AJC-15258

\begin{abstract}
Obesity is a major health problem worldwide and is associated with several pathological disorders, such as diabetes, cardiovascular disease and cancer. Lipase inhibition is one of the main therapies for obesity. Recent studies have shown the role of polyphenols in the prevention of obesity and obesity-related chronic diseases. Here, we evaluated the ability of polyphenol-rich extracts from peanut shell to inhibit pancreatic lipase activity in vitro. The results showed that the inhibition ratio of polyphenols extracts from peanut shells (PPS) on lipase can reached $41.5 \%$ at $0.29 \mathrm{mg} / \mathrm{mL}$. And the inhibition type of polyphenols extracts from peanut shells against pancreatic lipase is competitive inhibition. The inhibition constant Ki was $0.16 \mathrm{mg} / \mathrm{mL}$. Therefore, polyphenols extracts from peanut shells may be useful in treatment of obesity.
\end{abstract}

Keywords: Peanut shells, Polyphenols, Inhibition ratio, Pancreatic lipase.

\section{INTRODUCTION}

The prevalence of obesity has steadily increased over the past three decades both in the United States and worldwide. Obesity is regarded as a major risk factor for cardiovascular disease, certain cancers, diabetes and the combination of risk factors known as Metabolic Syndrome' ${ }^{1}$. It is well-known that energy imbalanced between calories consumed and expended is the fundamental cause of obesity. Triglyceride is the major energy source with the characteristics of high calories. Hence, inhibition of triglyceride absorption is considered to associate with the prevention of obesity and obesity-related diseases.

Lipases are important enzymes, responsible for the hydrolysis of $5070 \%$ of total dietary fats ${ }^{2}$. Therefore, the suppression of fat absorption by inhibiting the pancreatic lipase activity has become a major approach to prevent obesity ${ }^{3,4}$.

There have been reports that naturally-occurring polyphenols such as tannic acid, gallotannin, catechin and proanthocyanidin can inhibit pancreatic lipase because of its strong complexing abilities with lipases ${ }^{5-7}$ and thereby influence fat digestion and affect energy intake ${ }^{8}$.

Peanut shells are an abundant and inexpensive agricultural by-product of peanut (Arachis hypogea. L). Researchers found that peanut shells have pharmic functional components, such as polyphenols, luteolin, carotene, isosaponaretin except for coarse protein, carbohydrate and ash. Peanut shells polyphenols is being used as a potential natural antioxidant and there are no reports on the inhibitory activity of the peanut shells polyphenols extracts on the pancreatic lipase $\mathrm{e}^{9,10}$.

In this study, evaluation of polyphenols extracts from peanut shells in the inhibition of pancreatic lipase was carried out. Enzyme kinetic studies, using Michaelis-Menten and the derived Lineweaver-Burk (LB) equations were also performed to understand the possible mode of inhibition of polyphenols extracts from peanut shells.

\section{EXPERIMENTAL}

Peanut were purchased from a local market. The peanut produced in 2012 and the variety of peanut was "four-seed red" and the country of origin was Tailai county of Heilongjiang province, China. Peanut shells were kept in a sealed plastic bag and stored at $4{ }^{\circ} \mathrm{C}$. The polyphenols samples employed for HPLC analysis include pyrogallol, catechol, phlorglucinol, quercetin and luteolin and were purchased from Sigma Company (United States). Pancreatic lipase was purchased from Amresco Company (United States). All other chemicals were all purchased from the Beijing Chemical Agents Company (China).

Manufacturing process of polyphenols extracts from peanut shells: Polyphenols extracts from peanut shells were 
prepared by ultrahigh pressure method. A $50 \mathrm{~g}$ sample of peanut shells was defatted with $n$-hexane $(3400 \mathrm{~mL})$ for $10 \mathrm{~h}$ at room temperature and the $n$-hexane remaining in peanut shells was removed under reduced pressure in a vacuum oven. The defatted peanut shells (10 g) were macerated for 4 min with $250 \mathrm{~mL}$ aqueous ethanol $(75 \%, \mathrm{v} / \mathrm{v})$ in a high pressure facility (DL700, Dalong High-pressure Equipment Plant of Shanghai, China) at room temperature under $300 \mathrm{MPa}$. The extract was filtered and the residue was extracted again under the same conditions. The combined filtrates were evaporated to a final volume of $10 \mathrm{~mL}$ under vacuum in a rotary evaporator (RE-52 Model, Anting Electronic Instruments Plant of Shanghai, China) at $35^{\circ} \mathrm{C}$. The concentrated filtrates were lyophilized with a freeze dryer system (FD-1C, Kangbo Experiment Instruments Ltd., Beijing, China) to obtain the polyphenols extracts from peanut shells as a brown powder.

Pancreatic lipase activity assay: Lipase activity was determined as follows. In brief, the pancreatic lipase was titrated with $0.05 \mathrm{~mol} / \mathrm{L}$ sodium hydroxide using $2 \%$ glycerol triacetate $(\mathrm{v} / \mathrm{v})$ as the hydrolytic substrate. The reaction mixture without the enzyme was titrated as the blank control. One 'lipase unit' was defined as the amount of the enzyme that released $1 \mu \mathrm{mol}$ free fatty acid per minute under standard assay conditions.

To determine the inhibitory rate of lipase activity by polyphenols extracts from peanut shells, lipase activity was assayed at same glycerol triacetate concentrations $(2 \%)$ and in the presence of different polyphenols extracts from peanut shells concentrations $(0,0.07,0.14,0.2,0.29 \mathrm{mg} / \mathrm{mL})$. All samples were analyzed in triplicate.

The inhibitory ratio of polyphenols extracts from peanut shells was expressed as eqn. 1:

$$
\mathrm{I}=\left(1-\frac{\mathrm{A}}{\mathrm{A}_{0}}\right) \times 100 \%
$$

where $\mathrm{I}$ is the inhibitory rate of polyphenols extracts from peanut shells on the pancreatic lipase activity, $\mathrm{A}_{0}$ and $\mathrm{A}$ are the pancreatic lipase activities with or without polyphenols extracts from peanut shells, respectively.

Kinetic assessment: In order to probe kinetic parameters $\left(\mathrm{K}_{\mathrm{i}}\right)$ and type of inhibition, the effect of substrate concentration on the initial reaction velocity was studied using glycerol triacetate as a substrate through the hydrolysis reaction by the pancreatic lipase. The pancreatic lipase solutions with and without polyphenols extracts from peanut shells were incubated with various concentrations of emulsified glycerol triacetate with the final concentrations of 1.0, 1.5, 2.0, 2.5 and $3 \%(\mathrm{v} / \mathrm{v})$, respectively. In all cases, the enzymatic activity in phosphate buffer (pH 6.7-6.9) was assayed at $37 \%$ C. From the Lineweaver-Burk plots, the inhibitory constant $\left(\mathrm{K}_{\mathrm{i}}\right)$ and type of inhibition were determined.

\section{RESULTS AND DISCUSSION}

Determination polyphenols extracts from peanut shells: An ultrahigh pressure method was used for preparing polyphenols extracts from peanut shells. The extraction yields were used to evaluate the performance of ultrahigh pressure method. The extraction yield was defined as the ratio of polyphenols weight to sample weight. The highest yield of polyphenols extracts from peanut shells was found to be 71.3 $\mathrm{mg}$ of gallic acid equivalents (GAE)/g of shells under the optimized conditions (75\% ethanol-water solution, $300 \mathrm{MPa}$, 4 min, 1:25 ration of solid to liquid) that was got by orthogonal experiment method. A HPLC method was used to detect the characterization of polyphenols extracts from peanut shells (Table-1).

\begin{tabular}{ccc}
\multicolumn{3}{c}{$\begin{array}{c}\text { TABLE-1 } \\
\text { GRADIENT ELUTION }\end{array}$} \\
\hline Time (min) & A (\%) & B (\%) \\
\hline 0 & 74 & 26 \\
15 & 60 & 40 \\
30 & 65 & 35 \\
50 & 20 & 80 \\
60 & 90 & 10 \\
65 & 100 & 0 \\
\hline
\end{tabular}

Characterization of polyphenols extracts from peanut shells: Polyphenols extracts from peanut shells were a complex mixture, mostly made up of luteolin, pyrogallol, catechol, phlorglucinol, quercetin. The peaks of five representative fractions have been quantified comparing with standard sample pyrogallol, catechol, phlorglucinol, quercetin and luteolin. The biggest amount in polyphenols extracts from peanut shells was luteolin and other ingredients followed up. The profiles analyzed by HPLC were shown in Fig. 1.

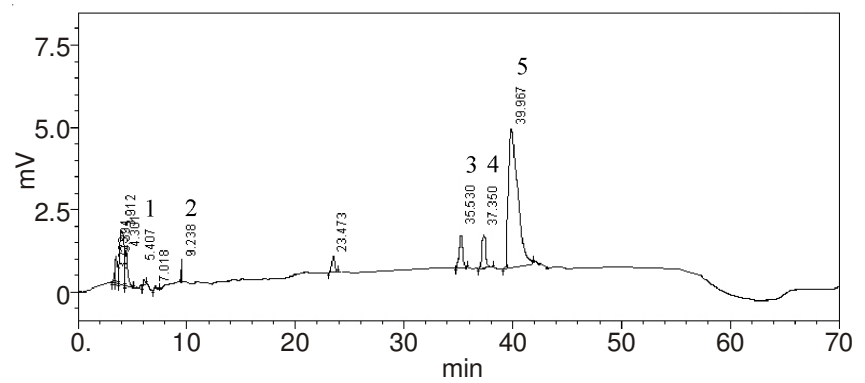

Fig. 1. Profiles of polyphenols extracts from peanut shells by HPLC. 1, pyrogallol; 2, catechol; 3, phlorglucinol; 4, quercetin; 5, luteolin

Inhibitory ratio of pancreatic lipase activity by polyphenols extracts from peanut shells: The inhibitory ratio of polyphenols extracts from peanut shells on pancreatic lipase activity and the influence of polyphenols extracts from peanut shells concentration on the inhibitory were shown in Table-2.

\begin{tabular}{ccccc}
\multicolumn{5}{c}{ TABLE-2 } \\
\multicolumn{5}{c}{$\begin{array}{c}\text { PEANUT SHELLS POLYPHENOLS } \\
\text { INHIBITION RATE OF LIPASE }\end{array}$} \\
\hline \multirow{2}{*}{ No } & $\begin{array}{c}\text { PPS Conc. } \\
(\%)\end{array}$ & $\begin{array}{c}\mathrm{V}(\mathrm{NaOH}) \\
(\mathrm{mL})\end{array}$ & $\begin{array}{c}\mathrm{E} \\
(\mathrm{U} / \mathrm{g})\end{array}$ & $\begin{array}{c}\text { Inhibition } \\
\text { ratio }(\%)\end{array}$ \\
\hline 1 & 0.07 & 0.6 & 0.027 & 17.9 \\
2 & 0.14 & 0.65 & 0.021 & 25.3 \\
3 & 0.2 & 0.72 & 0.019 & 34.9 \\
4 & 0.29 & 0.86 & 0.013 & 45.3 \\
\hline
\end{tabular}

It can be seen in Table-1, the inhibition ratio was advanced with the increase of polyphenols extracts from peanut shells concentration. The inhibition ratio was $45.3 \%$ with polyphenols extracts from peanut shells at $0.29 \mathrm{mg} / \mathrm{mL}$. Hence, 
polyphenols extracts from peanut shells might act as an antinutritional factor in terms of its potential to inhibit lipase activity.

Kinetics parameters assessment: To further characterize the inhibitory pattern of lipase by polyphenols extracts from peanut shells, we studied the reaction kinetics of lipase by varying the polyphenols extracts from peanut shells concentration and substrate concentration. Inhibition kinetics curve of polyphenols extracts from peanut shells against pancreatic lipase was shown in Fig. 2.

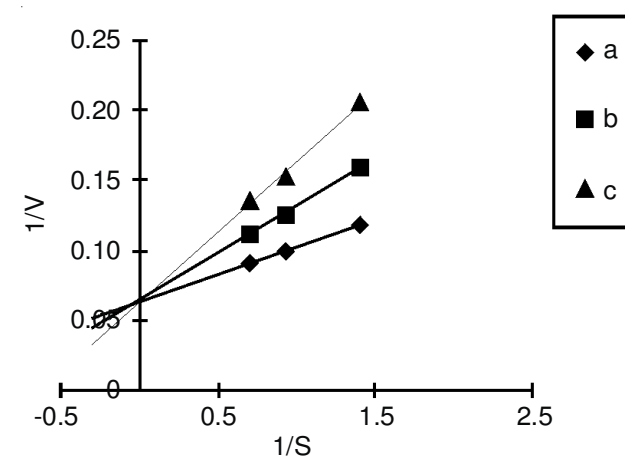

(A) Plots of $1 / \mathrm{V}$ versus $1 / \mathrm{S}$

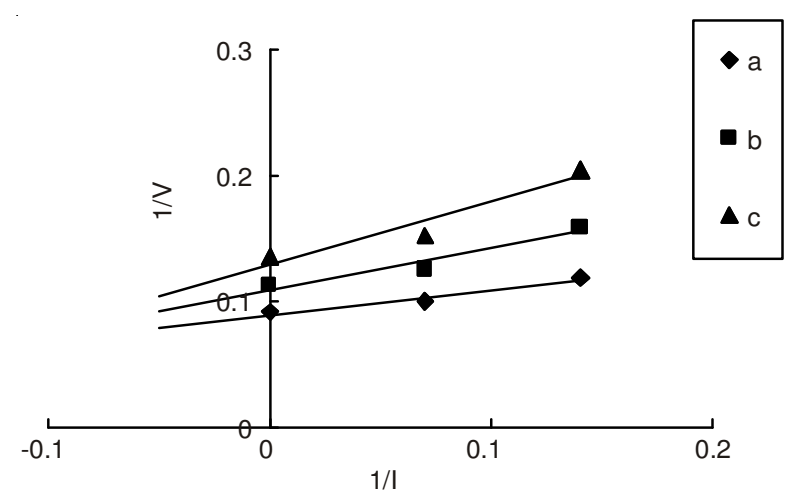

(B) Plots of $1 / \mathrm{N}$ versus $1 / \mathrm{l}$. a: $\mathrm{S}=1.42 \mathrm{~g} / \mathrm{mL}$ b: $S=1.06 \mathrm{~g} / \mathrm{mL}$ c: $S=0.69 \mathrm{~g} / \mathrm{mL}$

Fig. 2. Inhibition kinetics curve of polyphenols extracts from peanut shells against pancreatic lipase

Type of enzyme inhibition can be classed into two kinds of inhibition: reversible and irreversible inhibition according to binding mode and characteristics between enzyme and inhibitor ${ }^{11}$. The Lineweaver Burk plot in Fig. 2A shows the changes in $K_{m}$ values and $V_{\max }$ values for lipase inhibited by polyphenols extracts from peanut shells. In the presence of polyphenols extracts from peanut shells, the $\mathrm{K}_{\mathrm{m}}$ for lipase increased while the $\mathrm{V}_{\max }$ remained unchanged. Thus, the inhibition of lipase by polyphenols extracts from peanut shells was competitive. The Lineweaver Burk plot in Fig. 2B shows the inhibitory constant $\mathrm{K}_{\mathrm{i}}$ was $0.165 \mathrm{mg} / \mathrm{mL}$.

\section{Conclusion}

In this study, polyphenols extracts from peanut shells was shown to concentration-dependently inhibit pancreatic lipase activity (Table-2). The inhibitory rate increases with the increase of polyphenols extracts from peanut shells concentration. Furthermore, kinetic studies elucidate that polyphenols extracts from peanut shells does not change the $\mathrm{V}_{\max }$ value of PL but increases the $\mathrm{K}_{\mathrm{m}}$ value, indicating that polyphenols extracts from peanut shells competitively inhibits the pancreatic lipase activity and bind to the active site of pancreatic lipase protein. Namely, the interactions between pancreatic lipase and polyphenols extracts from peanut shells are specific, which cause significant denaturation or inactivation of the enzyme (Table-2 and Fig. 2).

Previous human clinical trials have shown that lipase inhibitors from plants can effectively reduce fat absorption to suppress weight gain in obese patients ${ }^{12-15}$, the findings in this work are not only very helpful to well understand the molecular interactions between pancreatic lipase and polyphenols extracts from peanut shells, but also greatly contribute to the development of the natural effective inhibitors for the prevention of human obesity in future. Therefore, polyphenols extracts from peanut shells may be useful in treatment of obesity. The effects of polyphenols extracts from peanut shells in animal experiments need further investigation.

\section{ACKNOWLEDGEMENTS}

The authors thank Jilin University and Ministry of Science, Technology and Innovation for the grant provided under the Intensified Research in Priority Areas Research Grant. This study was supported by Jilin Natural Science Foundation of China (20100137).

\section{REFERENCES}

1. M. Lean, J. Lara and J.O. Hill, BMJ, 333, 959 (2006).

2. M. Mukherjee, J. Mol. Catal., B, 22, 369 (2003).

3. A. Ballinger and S.I.R. Peikin, Eur. J. Pharm. Sci., 440, 109 (2002).

4. J.W. Yun, Phytochemistry, 71, 1625 (2010).

5. A.E. Hagerman, K.M. Riedl, G.A. Jones, K.N. Sovik, N.T. Ritchard, P.W. Hartzfeld and T.L. Riechel, J. Agric. Food Chem., 46, 1887 (1998).

6. S. Chethan and N.G. Malleshi, Food Chem., 105, 862 (2007).

7. E.G. de Mejia, M.V. Ramirez-Mares and S. Puangpraphant, Brain Behav. Immun., 23, 721 (2009).

8. G.J. McDougall and D. Stewart, Biofactors, 23, 189 (2005).

9. G.J. McDougall, N.N. Kulkarni and D. Stewart, Food Chem., 115, 193 (2009).

10. B. Shi, X.Q. He and E. Haslam, J.Am. Leather Chem. Assoc., 89, 98 (1994).

11. S. Chethan, Y.N. Sreerama and N.G. Malleshi, Food Chem., 111, 187 (2008).

12. D.S. Jang, G.Y. Lee, J. Kim, Y.M. Lee, J.M. Kim, Y.S. Kim and J.S. Kim, Arch. Pharm. Res., 31, 666 (2008).

13. Y.S. Kim, Y. Lee, J. Kim, E. Sohn, C.S. Kim, Y.M. Lee, K. Jo, S. Shin, Y. Song, J.H. Kim and J.S. Kim, Evid. Based Complement. Alternat. Med., Article ID 878365 (2012).

14. P. Slanc, B. Doljak, S. Kreft, M. Lunder, D. Janes and B. Strukelj, Phytother. Res., 23, 874 (2009).

15. B. Sternby, D. Hartmann, B. Borgstroom and P. Nilsson, Clin. Nutr., 21, 395 (2002). 